\section{Opportunistic infections in end stage liver disease}

\author{
Michele Bartoletti, Maddalena \\ Giannella, Sara Tedeschi, Pierluigi Viale \\ Infectious Diseases Unit, Department of \\ Medical and Surgical Sciences, \\ Sant'Orsola-Malpighi Hospital, \\ University of Bologna, Italy
}

\begin{abstract}
Liver cirrhosis is the 10th most common cause of death in Western world and infection is associated with a high morbidity and mortality, and represents the leading cause of acute liver decompensation. Patients with end-stage liver disease exhibit an important impairment of immune system. This condition, called cirrhosis-associated immune dysfunction, summarizes both local and systemic immune system alterations in liver cirrhosis that play a pivotal role in determining both the high incidence of infections and the ominous infections related mortality in this population. Another concerning feature of infections in cirrhotic patients is the growing prevalence of multidrug-resistant or extensively drug-resistant pathogens, which are associated with higher mortality, increased length of in-hospital stay and higher healthcare related costs if compared with infection caused by susceptible strains. Finally, patient with liver cirrhosis have several unique pathophysiological characteristics including hypoalbuminemia and reduction binding to proteins; altered distribution; altered clearance of the antimicrobials that can affect the pharmacokinetic/pharmacodynamic of antimicrobials.
\end{abstract}

\section{Introduction}

Liver cirrhosis is the 10th most common cause of death in Western world. ${ }^{1}$ Among the complications of the end-stage liver disease (ESLD), infection represents the leading cause of acute decompensation $^{2,3}$ and is associated with a high mortality ranging from 12 to $52 \%{ }^{4,5}$

Despite these patients are particularly prone to develop bacterial and fungal infections, ${ }^{6}$ the cirrhosis of the liver is not commonly considered a major immunodepressive condition. However, patients with ESLD exhibit an important impairment of immune system. This condition, called cirrhosis-associated immune dysfunction (CAID) summarizes both local and systemic immune system alterations in liver cirrhosis that play a pivotal role in determining both the high incidence of infections and the ominous infections related mortality in this patient population. ${ }^{7,8}$ Overall mortality of infected cirrhotic patients in around $30 \%$ at 1 month and more than $50 \%$ at 12 months. ${ }^{8}$ The high mortality rate of infections in cirrhotic patients is related not only to the direct effects of infections but, above all, to their pivotal role in triggering the condition of acute-on-chronic liver failure (ACLF). For this reason, infection is considered an important prognostic marker in patients with ESLD.

Another concerning feature of infections in cirrhotic patients is the growing prevalence of multidrug-resistant (MDR) or extensively drug-resistant (XDR) pathogens, which are associated with higher mortality, increased length of in-hospital stay and higher healthcare related costs if compared with infection caused by susceptible strains. ${ }^{9-11}$ In addition to these clinical features, the threat of MDR/XDR pathogens relies on their ability to rapidly spread to patients in absence of contact precautions. As a consequence, an important transmission of MDR gram-negative bacilli between patients is observed during outbreaks. ${ }^{12}$

In this setting a multifaceted approach is needed to face all the management challenges offered by patients with ESLD with infection. This include the knowledge of contemporary epidemiology, the development of prognostic tools and testing of novel therapeutic strategies.

\section{Epidemiology}

In light of the emerging threat of multidrug-resistant organisms (MDRO), mainly related the ominous spread of extendedspectrum beta-lactamase producing (ESBL) and carbapenem-resistant Enterobacteriaceae (CRE) and carbapenem resistant non-fermenting bacilli in the last decade, an increasing number of epidemiological studies were recently published. To better understand the evolution of epidemiology of bacterial and fungal infections in this setting the most representative studies are summarized in the Table 1..$^{13-21}$

The wide variability in term of site of infection and causative pathogens is mainly related to several factors. First, with exception of spontaneous bacterial peritonitis (SBP), there is no agreement for most of infection definitions and most studies did not adopted the widely agreed criteria for infection diagnosis used in non-cirrhotic population. Second, the epidemiology of infection is currently under constant evolution and may vary between centers. Third,
Correspondence: Michele Bartoletti, Infectious Diseases Unit, S. Orsola Malpighi Hospital, Via Massarenti 11, 40138 Bologna, Italy.

Tel.: +39.051.2143199 - Fax: +39.051.343500

E-mail: michele.bartoletti4@unibo.it

Key words: liver cirrhosis; bacterial infection; multidrug-resistant pathognes.

Contributions: MB, ST, MG, review of the literature; MB, ST, draft of the manuscript; $\mathrm{MG}$, $\mathrm{PV}$, Revision and final approval.

Contributions: the authors contributed equally.

Conflict of interest: the authors declare no potential conflict of interest.

Funding: none

Received for publication: 29 January 2018. Accepted for publication: 2 February 2018.

This work is licensed under a Creative Commons Attribution-NonCommercial 4.0 International License (CC BY-NC 4.0).

(C) Copyright M. Bartoletti et al., 2018

Licensee PAGEPress, Italy

Infectious Disease Reports 2018; 10:7621

doi:10.4081/idr.2018.7621

similarly to the previous point, different study site may be characterized by different level of commitment in the management of cirrhotic patients. Thus, tertiary sites with dedicated liver unit and access to a transplantation program may exhibit a population with more advanced stage of liver disease if compared with urban hospitals. Despite inhomogeneity, these studies clearly show that the rate of MDRO has increased dramatically and the improvement of the management of liver cirrhosis may have changed also the characteristics of infection site. In fact, in the studies published in the 90' and in the first years of the 21th Century the diagnosis of SBP was prevalent (24-56\% of cases). Conversely latter studies report a lower prevalence of SBP (8-18\%, excluding one paper that included bacterial ascites in the definition of SBP and reported $42 \%$ of such infections) and higher rate of bloodstream infection (6-28\%) and pneumonia (7-38\%).

Few studies reported to date differences in the kind of infection and in the causative pathogens in patients with alcoholic liver disease (ALD) and patients with other causes of liver cirrhosis. Previous studies on bloodstream infections (BSI) including mainly patients with alcoholic cirrhosis report a higher prevalence of gram-positive 
cocci (GPC) among the different etiologies of BSI. However most of these studies are old or characterized by a single-center design. ${ }^{22,23}$ In addition, infection in alcoholic cirrhosis seems to be characterized by higher frequency of ACLF, however conflicting results on the outcome are reported. ${ }^{3,24}$

\section{Risk factors for multidrug-resis- tant pathogens}

To date few studies evaluated risk factors for MDRO in the setting of cirrhosis (Table 2). ${ }^{4,9,25-29}$

Most of the reported studies focused on SBP whereas only 2 studies included all various sources of infection. The most reported risk factors for MDR were antibiotic exposure (antibiotic prophylaxis, use of third generation cephalosporines, fluoroquinolones or beta-lactams) and exposure to healthcare environment (i.e. hospital acquired or healthcare associated infections, previous hospital admission).

\section{Prognosis}

As mentioned before the high mortality rate of infections in cirrhotic patients is related not only to the direct effects of infections but, above all, to their pivotal role in triggering the condition of acute-onchronic liver failure (ACLF). In a prospective multicenter study (CANONIC study), bacterial infection was found to be the precipitating event of ACLF in $32 \%$ of cases. ${ }^{30}$ A further analysis of the CANONIC study revealed that $\mathrm{BSI}$, pneumonia and $\mathrm{SBP}$ are more likely to be associated with ACLF. In addition, in patients with grade I and II ACLF, the presence of bacterial or fungal infection was associated with a worse outcome. ${ }^{31}$ Similarly, in a single-center study enrolling patients with ACLF, bacterial infection was a predictor of 30-day mortality. ${ }^{32}$ Despite these findings, a better understanding of the interaction between bacterial infection and ACLF is needed. In fact, the specific role of different kind of infections in determining ACLF and its risk factors are not clearly established.

Infection is considered an important prognostic marker in patients with ESLD. In a large multicenter cohort of patients with biopsy-proven compensated viral cir- rhosis, the occurrence of a bacterial infection impaired survival both in HCV-infected (5-year survival: $60.2 \%$ vs $90.4 \%, \mathrm{P}<0.001$ ) and HBV-infected patients (5-year survival: $69.2 \%$ vs $97.6 \%, \mathrm{P}<0.001)$, representing the third cause of death (14.1\%) after liver failure and liver cancer. Similarly, in a singlecenter study enrolling 501 patients, bacterial infection was independently associated to mortality. The authors concluded that bacterial infection represents a different stage of the disease, which affect survival, even after recovery form an infectious episode. ${ }^{13}$

\section{Antimicrobial \\ pharmacokinetic/pharmacody- namic issues in liver cirrhosis}

Ensuring a prompt and appropriate empirical antimicrobial treatment for infections in liver cirrhosis is essential in liver cirrhosis..$^{33,34}$

The concept of appropriateness for empirical and targeted antimicrobial treatment relies on a right antimicrobial coverage associated with an appropriate exposure consistent with the drugs' pharmacokineticpharmacodynamic (PK/PD) features. PK

Table 1. Summary of epidemiological studies on patients with liver cirrhosis. Only studies including all different source of infection are reported.

\begin{tabular}{|c|c|c|c|c|c|c|c|c|}
\hline \multirow[t]{2}{*}{$\begin{array}{l}\text { Author/year/ } \\
\text { geographic area (ref) }\end{array}$} & \multirow[t]{2}{*}{ Population } & \multicolumn{4}{|c|}{$\begin{array}{l}\text { Most representative source } \\
\text { of infection, } \%\end{array}$} & \multicolumn{3}{|c|}{ Etiology (prevalence of MDR0), \% } \\
\hline & & SBP & UTI & LRTI & Primary BSI & $\begin{array}{c}\text { Gram- } \\
\text { negative }\end{array}$ & $\begin{array}{c}\text { Gram- } \\
\text { positive }\end{array}$ & Fungi \\
\hline \multicolumn{9}{|c|}{ Studies published in the $90^{\prime}$} \\
\hline Caly/1993/Brazil (14) & All cirrhotics & 31 & 25 & 25 & NR & $72(\mathrm{NR})$ & 28 & NR \\
\hline Toledo/1994/Spain (15) & All cirrhotics & 44 & 26 & 10 & 5 & 65 (61 E.coli) & 39 & NR \\
\hline \multicolumn{9}{|c|}{ Studies published from 2000 to 2015} \\
\hline Borzio/2001/Italy (16) & All cirrhotics & 23 & 41 & 17 & 21 & 46 & 49 & 4 \\
\hline Rosa/2000/Brazil (17) & All cirrhotics & 54 & 7 & 18 & NR & NR & NR & NR \\
\hline Fernandez/2002/Spain (18) & All cirrhotics & 24 & 19 & 13 & 5 & 45 & 47 & NR \\
\hline $\begin{array}{l}\text { Fernandez/2012/Spain (4) } \\
\text { /first series }\end{array}$ & All cirrhotics & 56 & 43 & 20 & 13 & $\begin{array}{c}44 \text { (MRSA 3\% } \\
\text { of all infections) }\end{array}$ & $\begin{array}{c}46 \text { (ESBL } 9 \% \\
\text { of all infections) }\end{array}$ & NR \\
\hline $\begin{array}{l}\text { Fernandez/2012/Spain (4)/ } \\
\text { second series }\end{array}$ & All cirrhotics & 20 & 25 & 13 & 13 & $\begin{array}{l}\text { MRSA 7\% of } \\
\text { all infections }\end{array}$ & $\begin{array}{c}\text { ESBL 7\% } \\
\text { of all infections }\end{array}$ & NR \\
\hline \multicolumn{9}{|c|}{ Studies published from 2015 to 2017} \\
\hline Merli/2015/Italy (9) & All cirrhotics & 8 & 61 & 12 & 6 & 47 & 47 & NR \\
\hline Park/2015/Korea (19) & $\begin{array}{l}\text { Alcoholic liver } \\
\text { disease }\end{array}$ & 9 & 4 & 38 & 4 & $\begin{array}{c}35 \\
\text { (MRSA 86\%) }\end{array}$ & $\begin{array}{c}63 \\
\text { (ESBL in } 42 \% \text { of } \\
\text { Enterobacteriaceae) }\end{array}$ & 2 \\
\hline Dionigi/2017/England (13) & All cirrhotics & 42 & 19 & 9 & 28 & 58 (MRSA 18\%) & 41 (ESBL 20\% of GNB) & NR \\
\hline $\begin{array}{l}\text { Salerno/2017/ (21) } \\
\text { Italy and England }\end{array}$ & All cirrhotics & 18 & 43 & 7 & 17 & 58 (MRSA 51\%) & $\begin{array}{c}47 \text { (44\% ESBL production } \\
\text { 9\% CR-GNB }\end{array}$ & n, 3 \\
\hline Piano/2017/Italy (21) & All cirrhotic & 33 & 23 & 14 & 13 & 46 & 47 & 7 \\
\hline
\end{tabular}

MDRO multidrug-resistant organisms; SBP spontaneous bacterial peritonitis; UTI urinary tract infection; LRTI low respiratory tract infection; BSI bloodstream infection; MRSA methicillin resistant Staphylococcus aureus; ESBL extended-spectrum beta-lactamase; CRE carbapenem-resistant Enterobacteriaceae; NR not reported 
variability is a major contributor to therapeutic failure: therefore to guarantee a correct exposure to antibiotics, timely administration of the right dose at the right schedule, according to the pathophysiological and immunological status of the patient, is required..$^{35}$

Patient with liver cirrhosis have several unique pathophysiological characteristics that can alter the PK/PD behavior and the in vivo activity of antimicrobial agents. These characteristics include: i) hypoalbuminemia and reduction binding to proteins; ii) altered distribution; iii) altered clearance of the antimicrobial. ${ }^{36}$

The reduction of antimicrobial protein binding is a consequence of decreased albumin production and accumulation of antibiotic binding inhibitors (such as bilirubin or $\alpha$-acid glycoprotein) in patients with liver cirrhosis. ${ }^{37}$ Depending on the degree of antibiotic protein binding, patients with liver cirrhosis may have, both in plasma and tissues, a higher fraction of unbound drug. This is the microbiologically active drug, but also the fraction that is cleared more rapidly through renal or hepatic pathways. Hence, patients with hypoalbuminemia have a higher proportion of drug escaping from the bloodstream and distributing into tissues, translating to increased distribution volume (Vd) and reduced or sometimes sub-therapeutic bloodstream concentrations required to treat severe infection. ${ }^{37,38}$

In patients with advanced liver cirrhosis, splanchnic congestion and fluid retention due to hypoalbuminemia and reduced renal blood flow can further increase the $\mathrm{Vd}$ for relatively hydrophilic antibiotics, such as beta-lactams, aminoglycosides, and vancomycin. As a result, most of the patients with ACLF presents with edema, ascites and third space expansion resulting in inadequate blood levels of these antibiotics. ${ }^{38,39}$ Therefore, larger loading and daily doses and are often required for hydrophilic antibiotics to achieve therapeutic blood levels.

On the other hand, increased Vd may also prolong the drug elimination irrespective of the clearance rates. ${ }^{37}$ In some patients with liver cirrhosis, antibiotics halflife is increased, paradoxically causing drug accumulation and potential for toxicity. ${ }^{40}$

Finally, the PK of antibiotics can be affected by liver-disease related changes in renal function that are very common in this population. Renal failure in liver cirrhosis is mainly due to a reduced renal perfusion secondary to a vasodilatation in the splanchnic circulation without a compensation of cardiac output. ${ }^{41}$ Although clearance of creatinine is widely accepted as a viable method for renal function assessment, several studies demonstrate that measured creatinine clearance from timed urine collection may overestimate the glomerular filtration rate in LC even in patients without hepatorenal syndrome. $^{42}$

Unfortunately, antibiotic PK/PD is rarely studied in patients with liver dysfunction, especially in patients with advanced cirrhosis and ascites (i.e. Child-Pugh Class C). This kind of patients are commonly excluded form phase 1, phase 2 and phase 3 studies. Consequently, there is currently lit- tle or no scientific basis for antibiotic doses currently administered to treat life-threatening infections in patients with advanced cirrhosis. Given the unpredictable drug exposure, therapeutic drug monitoring (TDM) might play a pivotal role for individualizing doses, both in lowering exposure-dependent toxicity and in ensuring an optimal drug exposure, especially for the treatment of serious infections or MDR pathogens.

Beta-lactams are commonly used and represent the first-line therapy of most infection in patients with liver cirrhosis. ${ }^{43}$ Beta-lactams are time-depending drugs which ensure the best effectiveness with a prolonged time of exposure above the pathogen minimal inhibitory concentration ( $>$ MIC). ${ }^{44}$ Previous studies in general population indicate that continuous or extended infusion of beta-lactams is associated to better drug exposure and higher $\mathrm{T}>\mathrm{MIC}$ and consequently better outcome for severe infection. ${ }^{45}$

According with the aforementioned pathophysiological characteristics, the cirrhotic patient seems an important setting to test continuous infusion of beta-lactams for treating severe infections.

\section{Conclusions}

Bacterial and fungal infection is common in the natural history of liver cirrhosis and seems to have an impact on prognosis. Several aspects of infections deserve further investigation, such as the interaction

Table 2 Risk factors for multidrug-resistant pathogens in patients with liver cirrhosis and infection.

\begin{tabular}{|c|c|c|c|}
\hline Author/Year/Geographic Area (Ref) & Kind of infections & Prevalence and kind of MDRO & Risk factors \\
\hline Merli/2015/Italy (9) & All bacterial infections & $51 \%$ & $\begin{array}{l}\text { Antibiotic prophylaxis; } \\
\text { HA or HCA infections }\end{array}$ \\
\hline Kim/2013/Korea (25) & Community-onset SBP & $32 \%$ of FQ resistant E.coli & $\begin{array}{l}\text { FQ use (30dd); Previous SBP episode; } \\
\text { Third-generation cephalosporin resistance }\end{array}$ \\
\hline Fernandez/2012/Spain (4)/ first series & All bacterial infections & & $\begin{array}{l}\text { Nosocomial origin of infection; } \\
\text { Long-term norfloxacinprophylaxis; } \\
\text { Recent infection by multi-resistant bacteria; } \\
\text { Recent use of b-lactams }\end{array}$ \\
\hline Chaulk/2013/Canada (26) & SBP & $\begin{array}{l}19 \% \text { third-generation } \\
\text { cephalosporin resistance }\end{array}$ & Nosocomial acquisition of infection \\
\hline Song/2009/Korea (27) & SBP & 7\% ESBL-Enterobacteriaceae & $\begin{array}{l}\text { Nosocomial acquisition; } \\
\text { Previous SBP episode }\end{array}$ \\
\hline Alexopolu/2012/Greece (28) & SBP & $24 \%$ & MELD score; HCA; Quinolone prophylaxis \\
\hline Ariza/2012/Spain (29) & HA and HCA SBP & $\begin{array}{l}42 \% \text { third } \\
\text { generation cephalosporine } \\
\text { resistance of HA SBP }\end{array}$ & $\begin{array}{l}\text { Diabetes mellitus; Upper GI bleeding; } \\
\text { Hospital acquired; Previous } 3^{\text {rd }} \mathrm{Gen} \\
\text { Cephalosporine use }\end{array}$ \\
\hline
\end{tabular}

MDRO, multidrug-resistant organisms; HA hospital associated; HCA healthcare associated; FQ fluoroquinolone; SBP spontaneous bacterial peritonitis; ESBL extended-spectrum beta-lactamase; MELD Model for EndStage Liver Disease; GI gastrointestinal 
between infection and ACLF. Additional studies are needed to assess novel therapeutic strategies like continuous infusion of beta-lactams on the outcome of infection in this setting.

\section{References}

1. Leon DA, McCambridge J. Liver cirrhosis mortality rates in Britain from 1950 to 2002: an analysis of routine data. Lancet 2006;367:52-6.

2. Leber B, Spindelboeck W, Stadlbauer V. Infectious complications of acute and chronic liver disease. Sem Respiratory crit care med 2012;33:80-95.

3. Moreau R, Jalan R, Gines P, et al. Acute-on-chronic liver failure is a distinct syndrome that develops in patients with acute decompensation of cirrhosis. Gastroenterology 2013;144:1426-37.

4. Fernandez J, Acevedo J, Castro M, et al. Prevalence and risk factors of infections by multiresistant bacteria in cirrhosis: a prospective study. Hepatology 2012;55:1551-61.

5. Kang CI, Song JH, Chung DR, et al. Liver cirrhosis as a risk factor for mortality in a national cohort of patients with bacteremia. J Infect 2011;63:33643.

6. Pant C, Olyaee M, Gilroy R, et al. Emergency department visits related to cirrhosis: a retrospective study of the nationwide emergency department sample 2006 to 2011. Medicine 2015;94:e308.

7. Albillos A, Lario M, Alvarez-Mon M. Cirrhosis-associated immune dysfunction: distinctive features and clinical relevance. J Hepatol 2014;61:1385-96.

8. Arvaniti V, D'Amico G, Fede G, et al. Infections in patients with cirrhosis increase mortality four-fold and should be used in determining prognosis. Gastroenterology 2010;139:1246-56.

9. Merli M, Lucidi C, Di Gregorio V, et al. The spread of multi drug resistant infections is leading to an increase in the empirical antibiotic treatment failure in cirrhosis: a prospective survey. PloS One 2015;10:e0127448.

10. Bartoletti M, Giannella M, Lewis R, et al. A prospective multicentre study of the epidemiology and outcomes of bloodstream infection in cirrhotic patients. Clin Microbiol Infect Dis 2017. Epub 2017/08/19.

11. Fernandez J, Bert F, Nicolas-Chanoine MH. The challenges of multi-drugresistance in hepatology. $\mathrm{J}$ Hepatol 2016.

12. Tacconelli E, Cataldo MA, Dancer SJ, et al. ESCMID guidelines for the man- agement of the infection control measures to reduce transmission of multidrug-resistant Gram-negative bacteria in hospitalized patients. Clin Microbiol Infect Dis 2014;20:1-55.

13. Dionigi E, Garcovich M, Borzio M, et al. Bacterial Infections Change Natural History of Cirrhosis Irrespective of Liver Disease Severity. Am J Gastroenterol 2017;112:588-96.

14. Caly WR, Strauss E. A prospective study of bacterial infections in patients with cirrhosis. J Hepatol 1993; 18:3538.

15. Toledo C, Flores C, Saenz M, et al. [Bacterial infections in hepatic cirrhosis]. Rev Med Chile 1994;122:788-94. [Article in Spanish]

16. Borzio M, Salerno F, Piantoni L, et al. Bacterial infection in patients with advanced cirrhosis: a multicentre prospective study. Dig Liver Dis 2001;33:41-8.

17. Rosa H, Silverio AO, Perini RF, Arruda CB. Bacterial infection in cirrhotic patients and its relationship with alcohol. Am J Gastroenterol 2000;95:12903.

18. Fernandez J, Navasa M, Gomez J, et al. Bacterial infections in cirrhosis: epidemiological changes with invasive procedures and norfloxacin prophylaxis. Hepatology 2002;35:140-8.

19. Park JK, Lee CH, Kim IH, et al. Clinical characteristics and prognostic impact of bacterial infection in hospitalized patients with alcoholic liver disease. J Korean Med Sci 2015;30:598605.

20. Salerno F, Borzio M, Pedicino C, et al. The impact of infection by multidrugresistant agents in patients with cirrhosis. A multicenter prospective study. Liver Int 2017;37:71-9.

21. Piano S, Bartoletti M, Tonon M, et al. Assessment of Sepsis-3 criteria and quick SOFA in patients with cirrhosis and bacterial infections. Gut 2017. Epub 2017/09/02.

22. Sargenti K, Prytz H, Nilsson E, et al. Bacterial infections in alcoholic and nonalcoholic liver cirrhosis. Eur J Gastroenterol Hepatol 2015;27:1080-6.

23. Campillo B, Richardet JP, Kheo T, Dupeyron C. Nosocomial spontaneous bacterial peritonitis and bacteremia in cirrhotic patients: impact of isolate type on prognosis and characteristics of infection. Clin Infect Dis 2002;35:1-10.

24. Gustot T, Fernandez J, Szabo G, et al. Sepsis in alcohol-related liver disease. J Hepatol 2017;67:1031-50.

25. Kim J, Kang CI, Joo EJ, et al. Risk factor of community-onset spontaneous bacterial peritonitis caused by fluoroquinolone-resistant Escherichia coli in patients with cirrhosis. Liver Int 2014;34:695-9.

26. Chaulk J, Carbonneau M, Qamar H, et al. Third-generation cephalosporinresistant spontaneous bacterial peritonitis: a single-centre experience and summary of existing studies. Canad J Gastroenterol Hepatol 2014;28:83-8.

27. Song KH, Jeon JH, Park WB, et al. Clinical outcomes of spontaneous bacterial peritonitis due to extended-spectrum beta-lactamase-producing Escherichia coli and Klebsiella species: a retrospective matched case-control study. BMC Infect Dis 2009;9:41.

28. Alexopoulou A, Papadopoulos N, Eliopoulos DG, et al. Increasing frequency of gram-positive cocci and gram-negative multidrug-resistant bacteria in spontaneous bacterial peritonitis. Liver Int 2013;33:975-81.

29. Ariza X, Castellote J, Lora-Tamayo J, et al. Risk factors for resistance to ceftriaxone and its impact on mortality in community, healthcare and nosocomial spontaneous bacterial peritonitis. J Hepatol 2012;56:825-32.

30. Moreau R, Jalan R, Gines P, et al. Acute-on-chronic liver failure is a distinct syndrome that develops in patients with acute decompensation of cirrhosis. Gastroenterology 2013;144:1426-37.

31. Fernandez J, Acevedo J, Wiest R, et al. Bacterial and fungal infections in acuteon-chronic liver failure: prevalence, characteristics and impact on prognosis. Gut 2017 Epub 2017/08/30.

32. Mucke MM, Rumyantseva T, Mucke VT, et al. Bacterial infection-triggered acute-on-chronic liver failure is associated with increased mortality. Liver Int 2017. Epub 2017/08/31.

33. Bartoletti M, Giannella M, Caraceni P, et al. Epidemiology and outcomes of bloodstream infection in patients with cirrhosis. J Hepatol 2014;61:51-8.

34. Park H, Jang KJ, Jang W, et al. Appropriate empirical antibiotic use and 30-d mortality in cirrhotic patients with bacteremia. World J Gastroenterol 2015;21:3587-92.

35. Pea F, Viale P. Bench-to-bedside review: Appropriate antibiotic therapy in severe sepsis and septic shock-does the dose matter? Crit Care 2009;13:214.

36. Westphal JF, Jehl F, Vetter D. Pharmacological, toxicologic, and microbiological considerations in the choice of initial antibiotic therapy for serious infections in patients with cirrhosis of the liver. Clin Infect Dis 1994;18:324-35. 
37. Roberts JA, Lipman J. Pharmacokinetic issues for antibiotics in the critically ill patient. Crit Care Med 2009;37:840-51.

38. Blot SI, Pea F, Lipman J. The effect of pathophysiology on pharmacokinetics in the critically ill patient-concepts appraised by the example of antimicrobial agents. Adv Drug Delivery Rev 2014;77:3-11.

39. Henriksen JH, Kiszka-Kanowitz M, Bendtsen F. Review article: volume expansion in patients with cirrhosis. Alimentary Pharmacol Therap 2002;16:12-23.

40. Verbeeck RK. Pharmacokinetics and dosage adjustment in patients with hepatic dysfunction. Eur J Clin Pharmacol 2008;64:1147-61.

41. Gines P, Schrier RW. Renal failure in cirrhosis. New Engl J Med 2009;361:1279-90.

42. Proulx NL, Akbari A, Garg AX, et al. Measured creatinine clearance from timed urine collections substantially overestimates glomerular filtration rate in patients with liver cirrhosis: a systematic review and individual patient meta-analysis. Nephrol Dial Transplant 2005;20:1617-22.

43. Jalan R, Fernandez J, Wiest R, et al. Bacterial infections in cirrhosis: a position statement based on the EASL
Special Conference 2013. J Hepatol 2014;60:1310-24.

44. Roberts JA, Paratz J, Paratz E, et al. Continuous infusion of beta-lactam antibiotics in severe infections: a review of its role. Int $\mathrm{J}$ Antimicrob Agents 2007;30:11-8.

45. Falagas ME, Tansarli GS, Ikawa K, Vardakas KZ. Clinical outcomes with extended or continuous versus shortterm intravenous infusion of carbapenems and piperacillin/tazobactam: a systematic review and meta-analysis. Clin Infect Dis 2013;56:272-82. 